\title{
REPENSAR A ESCOLA: DIRETRIZES PARA ANTEPROJETO DE UMA ESCOLA-PARQUE
}

\author{
SIQUEIRA, Maria Luíza Raitz (1); \\ OLIVEIRA, Gabriela Bastos de (2) \\ (1) Centro Universitário Estácio de Santa Catarina, Graduanda \\ e-mail:malu.siqueira@outlook.com \\ (2) Centro Universitário Estácio de Santa Catarina, Mestre \\ e-mail:gabriela.bastosarq@gmail.com
}

\begin{abstract}
RESUMO
A educação, no contexto do Brasil atual, ainda é muito distorcida e carente de melhorias, tanto no processo educacional quanto no espaço escolar. $\mathrm{O}$ ambiente escolar muitas vezes não é adequado ao tipo de uso e acaba prejudicando a aprendizagem do aluno. A partir disso, esta pesquisa corresponde ao desenvolvimento de diretrizes para elaboração de um anteprojeto de um Centro Educacional, embasado no conceito de escola-parque do educador Anísio Teixeira com o auxílio da teoria construtivista.
\end{abstract}

Palavras chave: escola-parque; arquitetura escolar; habitabilidade.

\begin{abstract}
Education, in the context of current Brazil, is still very distorted and lack ing in improvements, in both the educacional process and in the school environment. The school environment is often not appropriate to the type of use and ends up hampering student learning. After this, this research corresponds to the development of guidelines for the elaboration of a prelimi nary project of an Educational Center, based on the school-park concept of the educator Anísio Teixeira with the support of the constructivist theory.
\end{abstract}

Keywords: school-park ; school architecture; habitability.

\section{INTRODUÇÃO}

O termo escola provém do latim schola que refere-se a uma instituição criada com intuito de praticar o ensino entre alunos e professores (NOGUEIRA, 2017). Porém, a escola é muito mais do que somente um ambiente onde se adquire conhecimento. É no espaço escolar que temos as primeiras relações fora da família e que iniciamos nosso convívio social com os outros indivíduos. Graças a esse convívio, a criança passa a se enxergar como parte de um cenário coletivo, coexistindo com pessoas e lugares diferentes.

Segundo a Constituição Federal, art. 255 "a educação, direito de todos e dever do Estado e da família, será promovida e incentivada com a colaboração da sociedade, visando ao pleno desenvolvimento da pessoa, seu preparo para o exercício da cidadania e $s$ ua qualificação para o trabalho" (Brasil, 1988, p.137). 
Entretanto, as características tanto físicas quanto sensoriais desse espaço continuam sendo esquecidas no planejamento das escolas brasileiras. O espaço escolar, tão fundamental no processo de aprendizagem, hoje em sua maioria limita-se a um edifício qualquer, que muitas vezes não foi projetado para tal intuito e não atende as necessidades para um desenvolvimento psicossocial de qualidade do usuário.

Desta forma, não há uma integração entre o aluno e a escola, pois não se tem incentivo nem tempo para se estreitar essa relação. Esse tempo escolar muitas vezes não é valorizado, pois o espaço, a pedagogia, entre outras coisas não contribuem para seu aperfeiçoamento. Assim, a educação integral é um sistema que ajuda a promover essa interrelação entre o aluno, o ensino e o espaço.

Desde a primeira metade do século XX vem ocorrendo discussões acerca dessa metodologia escolar e como ela influencia positivamente o aluno. "Nesse sentido, na escola de tempo integral, o uso dos espaços e tempos é repensado, de modo a criar situações e oportunidades para o desenvolvimento das competências no campo linguísticoargumentativo, competência propositiva, competência decisória e competência auto inquiridora" (GONÇAL VES, 2006, p. 133)

Essa valorização de atividades diferenciadas auxilia na aprendizagem e no conhecimento adquirido e transforma a relação entre o aluno e o ensino. A educação integral é um meio de inserir essas atividades no cotidiano escolar, pois contempla um currículo mais completo e dinâmico, onde o aluno adquire conhecimento de acordo com o seu próprio tempo e escolhas.

Assim, acredita-se que uma educação em tempo integral, além de promover maior convívio entre os alunos e a escola, faz com que o indivíduo desenvolva suas habilidades e conhecimentos em outras áreas além daquelas abordadas pelo ensino tradicional (EBOLI, 1969). Um programa diferenciado, mesmo que em tempo integral, é muito mais atrativo e cognitivo do que apenas uma abordagem usual e muitas vezes ultrapassada.

O conceito escola-parque do educador Anísio Teixeira contempla este fator. Sua ideia defendia uma educação pública, gratuita, integral, laica e obrigatória, possibilitando o acesso a uma educação de qualidade. De acordo com Eboli (1969), esse conceito também aborda a autonomia do aluno, onde o indivíduo é o sujeito ativo no seu processo de ensinoaprendizagem.

Dessa maneira, a presente pesquisa tem como objetivo analisar e propor diretrizes para o desenvolvimento de anteprojeto arquitetônico de um Centro Educacional voltado para o conceito de escola-parque do educador Anísio Teixeira com base na teoria construtivista. A necessidade de realização desta pesquisa justifica-se pela importância deste espaço no cotidiano dos usuários e como esse assunto é pouco explorado e levado em consideração, principalmente nas escolas brasileiras.

\section{REFERENCIAL TEÓRICO}

De certa forma, o resultado bem-sucedido de uma edificação é conseguir atender de forma clara as necessidades dos usuários daquele espaço. A divisão dos espaços, seu tamanho, suas características e como este espaço pode afetar as atividades ali realizadas são conceitos que devem ser pensados de acordo com as particularidades e contextualizações de cada ambiente (KOWALTOWSKI, 2011). Essas particularidades devem ser previamente estudadas e analisadas, a fim de promover uma maior otimização do local.

Ao projetar uma edificação para uso educacional é preciso "[...] entender como é visto o espaço da escola pelas pessoas que a utilizam e qual a sua relação com a aprendizagem. $E$ 


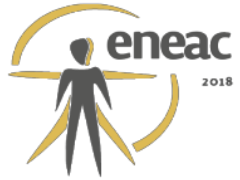

buscar compreender de que maneira o espaço físico escolar interfere no cotidiano da escola" (MELO, 2012, p.5).

Assim, na fundamentação teórica desta pesquisa foi analisado o histórico da educação no Brasil desde os seus primórdios, com a chegada dos jesuítas em 1549, até a manifestação da Escola Nova e sua ruptura com a escola tradicional. Além disso, fez -se uma análise e descrição do conceito de Escola-Parque do educador Anísio Teixeira, onde foram contextualizadas as suas três principais características: a educação em tempo integral, a escola como ponto de convívio e sociabilidade e o uso da arquitetura como aliada a um ambiente favorável de ensino (EBOLI, 1969).

Outro ponto abordado foi a teoria construtivista do filósofo Jean Piaget e seus aspectos quanto a sua implementação no espaço escolar, já que essa teoria pressupõe o conhecimento como algo a ser construído e embasado pelo aluno através de suas ações, interações e atividades com o ambiente. Desta forma, "o projeto arquitetônico deve dialogar diretamente com o projeto pedagógico" (KOWALTOWSKI, 2011).

Em relação às leis relevantes ao assunto, foi estudada a Lei de Diretrizes e Bases da Educação (LDB) sancionada em 1996, que estabelece critérios para o funcionamento e a regularização do sistema educacional brasileiro. É através da LDB que são estabelecidos os princípios gerais da educação e suas finalidades, bem como os recursos financeiros, a formação do aluno e as diretrizes para os profissionais da educação.

Por fim, foi explorada a relação entre o aluno e ambiente físico escolar, através do comportamento do indivíduo dentro desse espaço. De acordo com Kowaltowski (2011, p.

40) "configurações espaciais específicas, como nichos, caminhos, acessos, distribuição de luz no ambiente (relação entre as aberturas e o espaço físico), intensidade das cores, texturas e seus respectivos efeitos sobre o usuário [...] são discutidas para a humanização da arquitetura e sua inter-relação com oindivíduo".

Nesse sentido, a psicologia ambiental é a área que estuda essas inter-relações entre o ser humano e o ambiente na qual ele está inserido e também foi abordada durante esta pesquisa. Esta área está profundamente ligada à arquitetura, pois tem o mesmo princípio e "partem das relações - ambientes (construído) - habitantes e seu comportamento". (MELO, 1991, p 90). Essa ligação pode ser usada como benefício na hora de projetar um ambiente qualificado para atender as necessidades do ocupante e promover uma melhorar relação com o espaço.

\section{MÉTODOS E TÉCNICAS}

A pesquisa desenvolveu-se através de estudo de caso, que consiste em pesquisar e estudar projetos referenciais com o objetivo de identificar os pontos positivos e negativos dos projetos e, portanto, servir como referência para avaliar a melhor forma de se projetar (GUEDES, 2015). Entre as escolas estudadas, a seguinte pesquisa foi composta a partir de três estudos de caso diretos, onde a autora foi in loco para ter acesso às informações. Foram elas:

- Escola Alere, educação privada e integral (Florianópolis, SC);

- E.E.B. Professor José Brasilício, educação pública e tradicional (Biguaçu, SC)

- Escola Sarapiquá, educação privada e construtivista (Florianópolis, SC);

E dois estudos de caso indireto, realizados através de referências bibliográficas eletrônicas: 
- Escola Parque de Salvador, primeira escola a exercer o conceito de Teixeira (Salvador, BA)

- Escola Parque Gávea 355, educação integral segundo o conceito de Teixeira (Rio de Janeiro, RJ).

Nos estudos de caso direto foram utilizados técnicas de observação, entrevistas e a dinâmica do Jogo de Imagens e Palavras, técnica desenvolvida pelo arquiteto argelino Saddek Rehal. Esta dinâmica consiste na reflexão das ideias dos participantes, sobre suas experiências de vida e sobre o que é possível mudar e/ou melhorar nos ambientes por eles vivenciados. São utilizadas imagens para auxiliar os participantes na expressão de sentimentos e na discussão do assunto. A aplicação possui três etapas: na primeira são feitas perguntas instigantes ao grupo e relevantes ao tema; na segunda, os participantes escolhem as imagens que possuem relação à pergunta lançada; e na terceira, respondem às indagações referentes ao por que das escolhas feitas (SAVI apud REHAL, 2002).

Diante do exposto, a autora aplicou a técnica com 30 alunos do $3^{\circ}$ ano do ensino fundamental I da escola Professor José Brasílicio (Biguaçu/SC) com faixa etária entre 7 (sete) e 9 (nove) anos. Por se tratar de uma turma grande, foi utilizado um projetor de multimídia a fim de mostrar as imagens escolhidas para o jogo e um questionário para cada aluno transcrever sua escolha. Com base nos estudos de Oliveira (2013), foram estabelecidas 10 (dez) diferentes atividades (Tabela 1) que são realizadas diariamente na escola e que fazem parte do cotidiano das crianças.

Tabela 1- Descrição das atividades

\begin{tabular}{|c|c|}
\hline ATIVIDADE & DESCRIÇÃO \\
\hline ESTUDAR & $\begin{array}{l}\text { Adquirir conhecimento ou habilidade. Atividade normalmente realizada em } \\
\text { uma sala, onde seja possível escrever, ler e conversar. }\end{array}$ \\
\hline LER & $\begin{array}{l}\text { Decifrar e estudar uma determinada sequência de palavras. Atividade } \\
\text { concebida preferencialmente em local silencioso e aconchegante, com } \\
\text { iluminação adequada. }\end{array}$ \\
\hline BRINCAR & $\begin{array}{c}\text { Distrair-se e entreter-se com alguma atividade geralmente lúdica. Pode ser } \\
\text { realizada nos mais variados ambientes, de acordo com a faixa etária e com a } \\
\text { brincadeira. }\end{array}$ \\
\hline EXERCITAR & $\begin{array}{c}\text { Exercer ou praticar alguma atividade normalmente física ou que envolva algum } \\
\text { esporte. Deve ser executada em ambientes adequados a cada tipo de } \\
\text { atividade. }\end{array}$ \\
\hline DESCANSAR & $\begin{array}{c}\text { Ter ou proporcionar tranquilidade, acalmar-se. Essa atividade precisa } \\
\text { necessariamente ser realizada em espaços serenos e quietos que favoreçam } \\
\text { o bem-estar do indivíduo. }\end{array}$ \\
\hline COMER & $\begin{array}{l}\text { Ingerir ou experimentar alimentos. Atividade em grupo, deve ser efetuada em } \\
\text { locais limpos e arejados, com espaço para sentar. }\end{array}$ \\
\hline CUIDAR DE SI & $\begin{array}{l}\text { Higiene pessoal, hábitos para preservar a saúde. Precisa de um espaço } \\
\text { específico, limpo e arejado, além de privativo. }\end{array}$ \\
\hline DESENHAR & $\begin{array}{c}\text { Representar graficamente uma ideia. Atividade desenvolvida em meio criativo } \\
\text { e espaçoso, onde seja possível sentar. }\end{array}$ \\
\hline
\end{tabular}

Fonte: Autora (2017) 


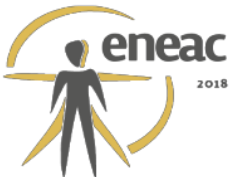

Tabela 1 (continuação) - Descrição das atividades

\begin{tabular}{|c|c|}
\hline ATIVIDADE & DESCRIÇÃO \\
\hline ASSISTIR FILMES & $\begin{array}{r}\text { Atividade em grupo de ver e ouvir filmes. É necessário um espaço } \\
\text { aconchegante e apropriado para tal atividade, com espaços confortáveis para } \\
\text { sentar. }\end{array}$ \\
\hline FESTEJAR & $\begin{array}{r}\text { Comemorar ou celebrar algo. Atividade em grupo, geralmente desenvolvida } \\
\text { em espaços grandes e de iluminação adequada. }\end{array}$ \\
\hline
\end{tabular}

Fonte: Autora (2017)

Em seguida, para cada atividade foram escolhidas 4 (quatro) imagens, num total de 40 (Tabela 2). A escolha destas imagens se deu por alguns critérios. Foram escolhidos espaços bem elaborados e que chamam atenção, mas também ocorreu a situação contrária, com ambientes desqualificados para tais usos a fim de ter uma comparação e diálogo entre os alunos e a pesquisadora. Outros critérios foram ambientes com espaços e mobiliários diferenciados e com a presença de cores, ambientes tradicionais e monocromáticos, espaços físicos amplos e limpos, ambientes com contato exterior e sem contato; ambientes com muita natureza e espaços livres, ambientes lúdicos e criativos.

Tabela 2 - Exemplo de imagens do Jogo de Imagens e Palavras

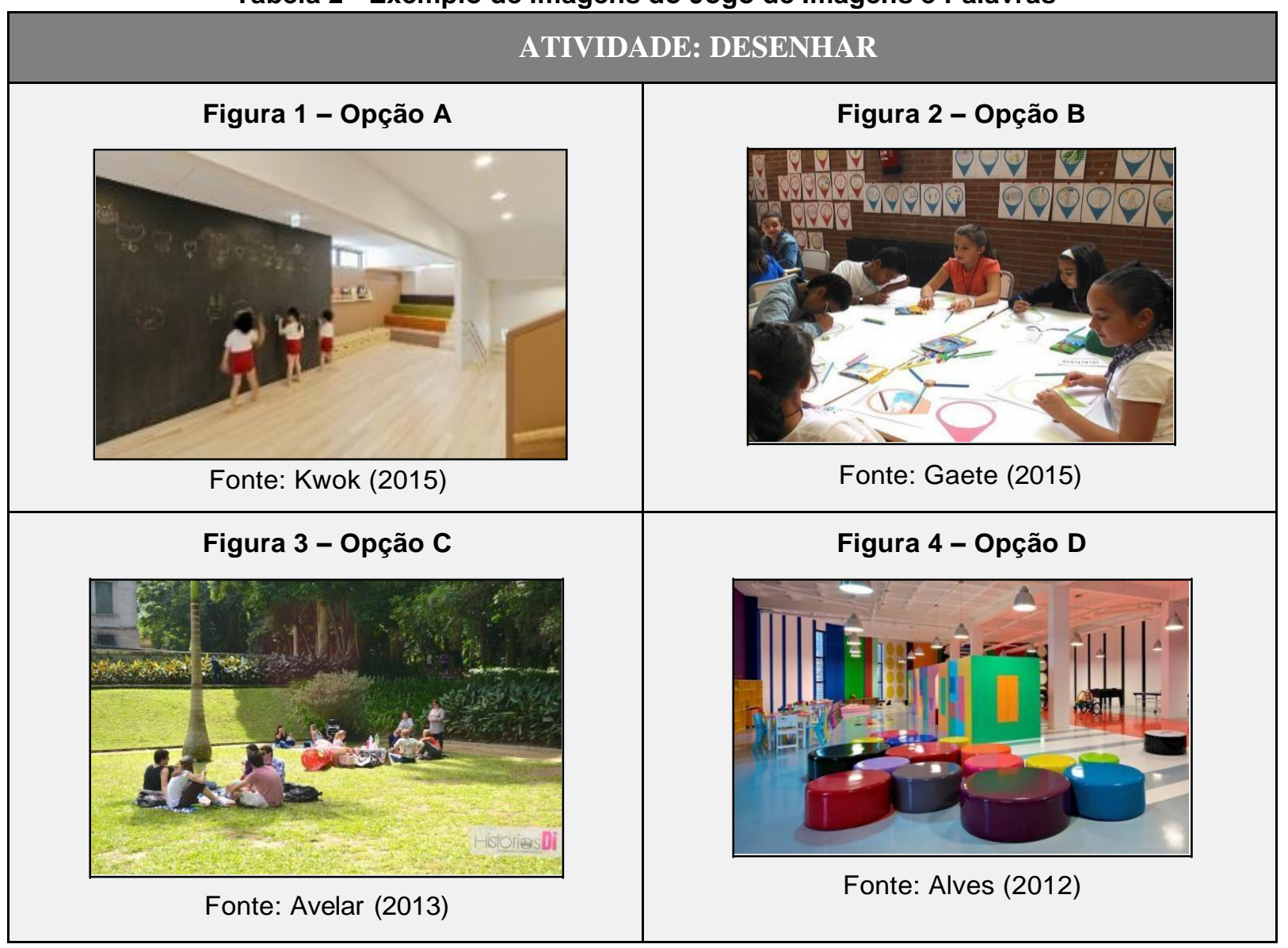

Fonte: Autora (2017) 


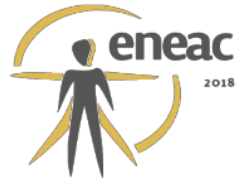

O jogo e todas as discussões acerca das imagens levaram aproximadamente 30 minutos. Os alunos se mantiveram atentos à técnica durante todo tempo, mantendo discussões sempre que possível. Por fim, com o estudo dos referenciais projetuais, foi possível perceber as principais características de cada escola, bem como suas diferenças de acordo com suas propostas pedagógicas. Além disso, notou-se a diversidade de soluções adotadas por cada instituição conforme suas necessidades físicas, apesar de todas apresentarem um uso comum.

Um dos pontos primordiais da pesquisa foi ter acesso a informações sobre o conceito de educação integral e a teoria construtivista, dois pontos muito abordados no trabalho e que necessitavam de uma maior explanação. Como proposta pedagógica, a educação integral precisa de uma boa estrutura física, pois o aluno permanecerá na escola durante o dia inteiro e consequentemente fará todas as suas refeições ali. Outro fator que proporcionou muitas informações e um contato maior para a autora foi a realização do Jogo de Imagens e Palavras. A partir dessa dinâmica, foi possível discernir as características e diretrizes para cada ambiente de acordo com a atividade ali ofertada e os desejos dos usuários.

\section{DIRETRIZES E CONDICIONATES PROJETUAIS}

A partir do estudo prévio tanto do referencial teórico, como dos estudos de caso e dos métodos utilizados para tal pesquisa, foram estabelecidos diretrizes e parâmetros para a definição do futuro terreno e dos aspectos físico-ambientais referentes à área escolhida para o anteprojeto, bem como suas características e condicionantes legais.

\subsection{Critérios para Escolha do Terreno}

A escolha do terreno para o anteprojeto precisa seguir algumas exigências favoráveis à implantação de um ambiente escolar. A necessidade da região por escolas, o entorno e o uso do solo, a infraestrutura do local e as circunstâncias naturais do lote (bioclimáticas e topográficas) constituem um conjunto de características que definem o melhor terreno para uso escolar. Abaixo encontram-se descritos alguns aspectos e sua importância para a definição do terreno:

- Quanto à necessidade da área: o MEC estipula uma distância de no máximo 2 (dois) km entre a casa do aluno e a escola.

- Quanto ao entorno: é preferível uma predominância residencial nas imediações do terreno, pois "os níveis elevados de ruído podem ser prejudiciais na alfabetização das crianças, por interferirem no foco de atenção e na comunicação entre professor e aluno" (AZEVEDO, 2002).

= Quanto à infraestrutura: "a seleção dos terrenos deve estar condicionada também à disponibilidade de infraestrutura urbana na região, envolvendo a existência de saneamento básico, de rede elétrica, rede telefônica e de transporte compatíveis" (ARAÚJO, 2014).

- Quanto aos aspectos naturais do lote: na escolha do terreno deve-se levar em conta a topografia, "onde o terreno deve ser preferencialmente plano para tornar o acesso à escola o mais fácil possível" (CARVALHO, 2008).

A definição do terreno deve seguir os critérios explanados acima, além de levar em conta as condicionantes legais da região escolhida. 


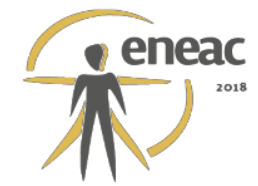

\subsection{Condicionantes Legais}

Para maior discernimento e aprofundamento da proposta, a pesquisadora baseou-se nas condicionantes do munícipio de Biguaçu e do estado de Santa Catarina. Dessa forma, foi possível definir as legislações básicas para uma futura implementação da escola nesta região. Entre as condicionantes legais usadas para desenvolvimento do anteprojeto estão:

- o Plano Diretor e o Código de Obras de Biguaçu, referentes a diretrizes urbanísticas a serem adotadas em projetos e construções no munícipio;

- as Instruções Normativas (IN) do Corpo de Bombeiros Militar de Santa Catarina (CBM/SC), pertinentes a procedimentos e requisitos mínimos de segurança contra incêndio;

- a Norma Brasileira (NBR) 9050 - Acessibilidade a edificações, mobiliário, espaços e equipamentos urbanos;

- e alguns documentos do Ministério da Educação (MEC) que explanam os parâmetros básicos para ambientes escolares, entre eles a cartilha de Parâmetros Básicos de Infraestrutura para Instituições de Educação Infantil (BRASIL, 2006) e o Manual de Elaboração de Projetos de Edifícios Escolares da Cidade do Rio de Janeiro criado pelo Instituto Brasileiro de Administração Municipal (IBAM, 1996).

\subsection{Recomendações ao Anteprojeto Arquitetônico}

A partir do estudo das condicionantes indicadas acima, analisou-se alguns critérios de acordo com cada etapa de projeto, a fim de proporcionar melhor entendimento das características mínimas para implantação do edifício escolar.

\subsubsection{Características do Terreno e Localização}

- Considerar a relação entre a área construída e as áreas livres, de paisagismo (Figura 5), recreação, entre outras (BRASIL, 2006).

\section{Figura 5 - Bosque como elemento de paisagismo e convivência}

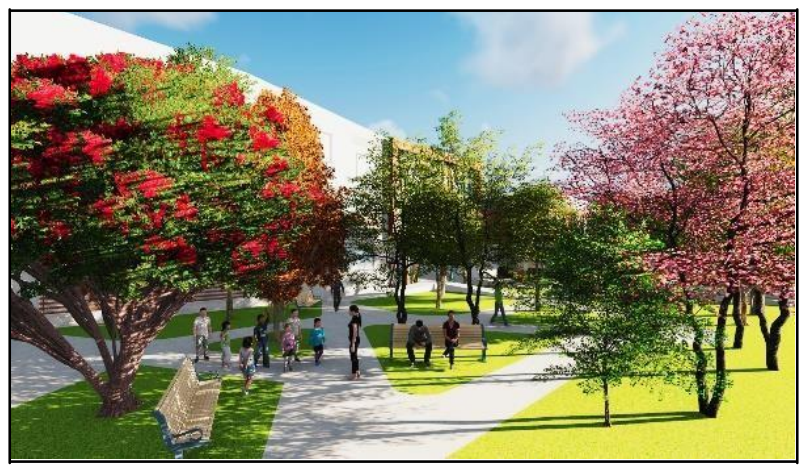

Fonte: Autora (2017)

- Recomenda-se que a área construída corresponda a 1/3 da área total do terreno e não ültrapasse taxa de ocupação maior que 50\% (IBAM, 1996). 


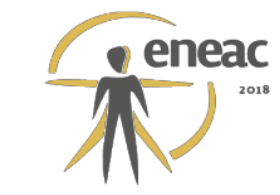

- Evitar a localização próxima a zonas industriais com índice de poluição significativo e próximo a antenas de transmissão (BRASIL, 2006).

- Nas entradas é necessário prever área de espera externa junto ao alinhamento para diluir aglomerações durante os horários de pico (IBAM, 1996).

\subsubsection{Características da Arquitetura}

- Considerar a configuração de uma arquitetura que se integre ao clima, considerando sua forma, materiais que sejam compatíveis e elementos de proteção solar (Figura 6).

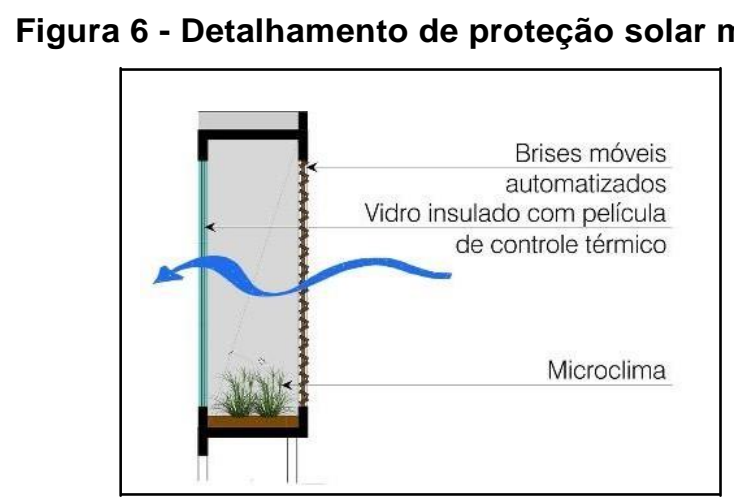

Fonte: Autora (2017)

- Considerar a insolação e a direção dos ventos dominantes, tendo em vista sempre melhores condições térmicas nos espaços (BRASIL, 2006).

- Prever existência de ventilação cruzada nos ambientes através de aberturas em paredes opostas e em alturas diferenciadas e privilegiar a iluminação natural sempre que possível.

\subsubsection{Características do ambiente e sua organização espacial}

- Promover ambientes próximos, ordenados e que estimulem a convivência em grupo (Figura 7) e contribuam para atividades coletivas.

Figura 7 - Áreas de convivência próximas a s salas de aula

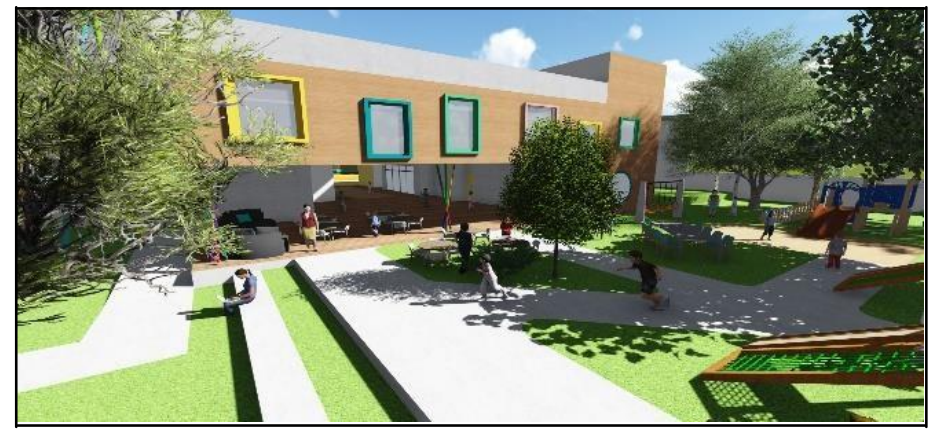

Fonte: Autora (2017) 


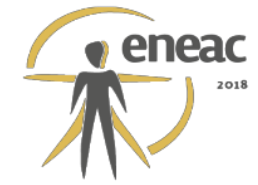

- Os banheiros devem ter fácil acesso e serem próximos as salas de atividades e área de recreação e vivência, além de conter equipamentos que facilitem o uso.

- O setor administrativo deve estar próximo ao acesso principal e ter espaço para recepção dos pais. As salas de aula devem ter privacidade e serem isoladas acusticamente.

- As áreas destinadas ao preparo dos alimentos devem ser reservadas e de difícil acesso às crianças. Portas à meia altura proporcionam segurança e possibilitam a ventilação.

- Considerar a escala da criança em todos os ambientes, promovendo uma orientação espaço-temporal e segurança (Figura 8).

Figura 8 - Exemplo de sala de aula para usuários de 6 (seis) anos

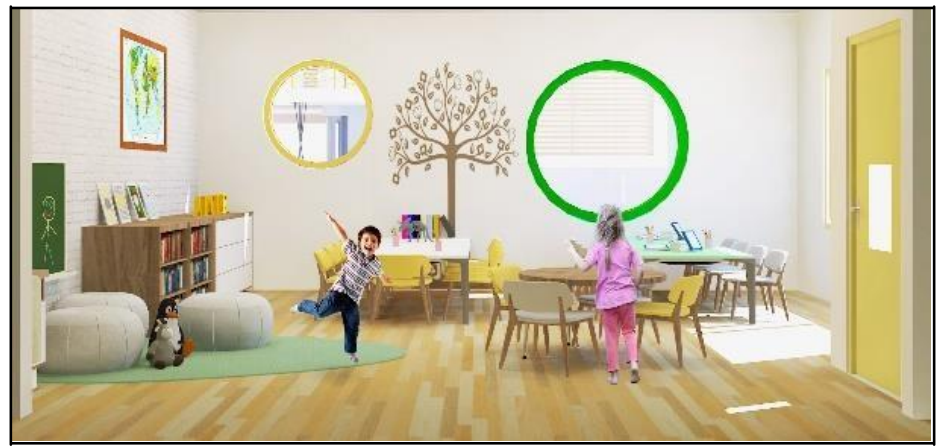

Fonte: Autora (2017)

- Em ambientes muito amplos e diversos, deve-se incluir elementos estruturados (caminhos definidos, tratamento paisagístico, áreas de vivência coletiva, mobiliário externo compatível com o tamanho das crianças) (Figura 9).

Figura 9 - Exemplo de área de vivência coletiva

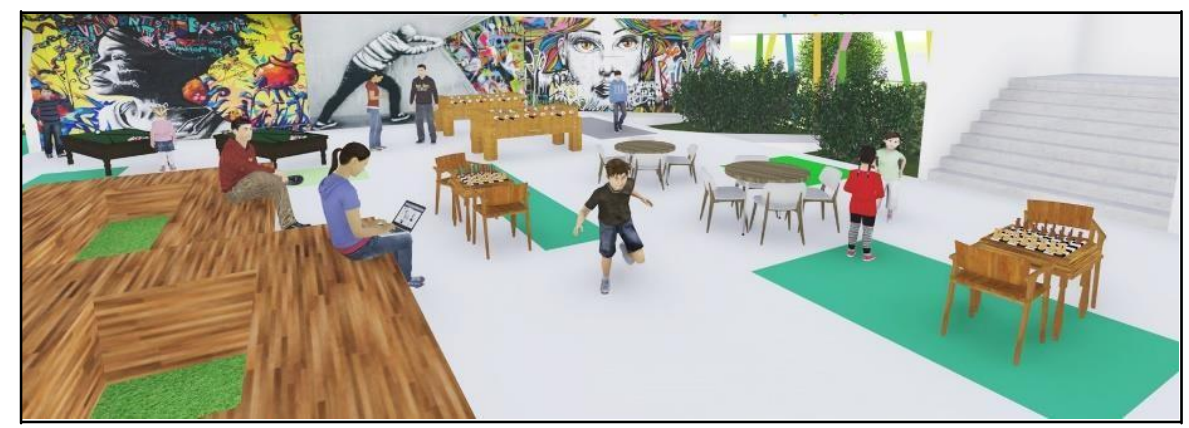

Fonte: Autora (2017)

- O mobiliário deve ter tamanho adequado a cada faixa etária e deve ser definido em função da sua resistência, durabilidade, manutenção e segurança (IBAM, 1996).

- As janelas, além de proporcionarem ventilação e iluminação adequadas, devem estar sempre ao alcance do usuário mirim (Figura 10), estabelecendo a integração e a visualização do ambiente externo, além de propiciar conceitos topológicos (dentro/fora, longe/perto, etc.). 


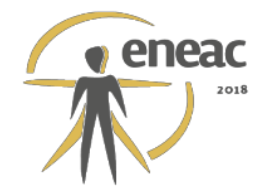

Figura 10 - Exemplo de fachada utilizando janela s em diferentes tamanhos e alturas

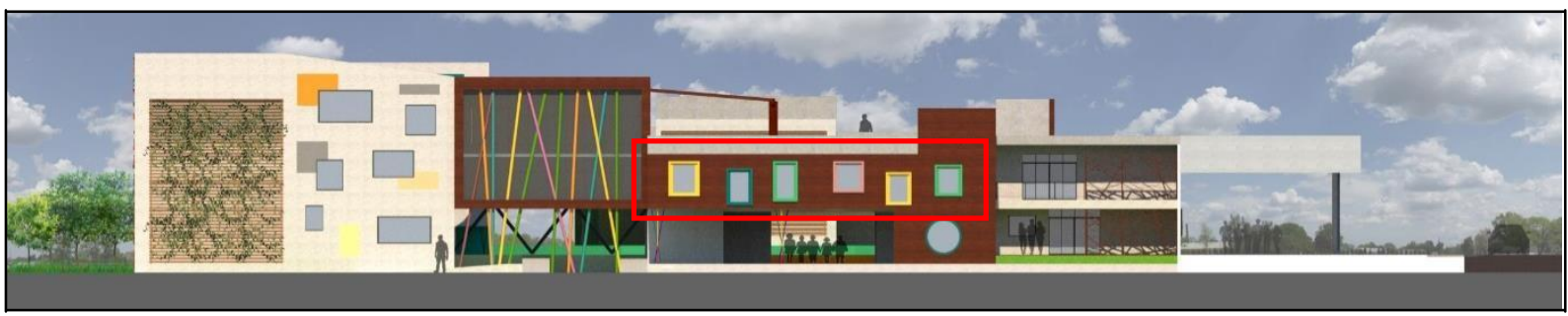

Fonte: Autora (2017)

\section{CONSIDERAÇÕES FINAIS}

A instituição escolar é início de todo convívio social que o ser humano terá durante sua vida. É a partir desse convívio que o cenário coletivo passa a fazer parte do cotidiano das crianças, tornando-a um ser pensante e integrado a sociedade. Desta forma, é imprescindível que este espaço esteja de acordo com as necessidades do ensino que ali será aplicado. Porém, diante da realidade atual faz-se necessário um novo olhar sobre as escolas públicas e como seu ambiente vem sendo desenvolvido no país.

Com o ambiente escolar sendo um espaço único e com necessidades específicas, foi necessária maior preocupação em conhecer a legislação, principalmente as que explanam especificamente sobre as condições mínimas deste ambiente, como suas medidas mínimas, características de ventilação, insolação, entre outros.

Assim, todos os estudos e a proposta conceitual arquitetônica deste anteprojeto trouxeram o entendimento a edificação escolar não deve somente atender as recomendações necessários e requisitos mínimos e assim se tornar apenas um local de ensino, mas também servir como cenário de interação, aprendizagem e troca de experiências.

Por fim, espera-se que esta pesquisa possa contribuir para o desenvolvimento de futuros projetos que busquem melhores condições para edificações escolares e que possam promover um ensino de qualidade com o auxílio da arquitetura.

\section{REFERÊNCIAS BIBLIOGRÁFICAS}

ALVES, Jorge. Espaço de Recreação Infanto-juvenil / David Guerra. ArchDaily Global (online), 2012. Disponível em: <https://www.archdaily.com.br/br/01-42463/espaco-de-recreacao-infanto-juvenildavid-guerra>. Acesso em: 22 de abr. de 2017.

ARAÚJO, Jéssica Medeiros. Flex Kids: proposta para uma instituição de educação infantil espacialmente flexível. 2014. 194 f. TCC (Graduação) - Curso de Arquitetura e Urbanismo, Centro de Tecnlogia, Universidade Federal do Rio Grande do Norte, Natal, 2014. Disponível em: <https://monografias.ufrn.br/jspui/handle/123456789/856>. Acesso em: 18 mar. 2017.

ASSOCIAÇÃO BRASILEIRA DE NORMAS TÉCNICAS. NBR 9050: Acessibilidade a edifcações, mobiliário, espaços e equipamentos urbanos. Rio de Janeiro: Abnt, 2015. 148 p. Disponível em: <http://www.ufpb.br/cia/contents/manuais/abnt-nbr9050-edicao-2015.pdf>. Acesso em: 10 mai. 2017.

AVELAR, Diana S. B. Rio de Janeiro: descobrindo o Parque Lage. Rodando pelo Mundo, 2013. Disponível em: <http://www.rodandopelomundo.com/2013/05/31/rio-de-janeiro-descobrindo-osencantos-o-parque-lage/>. Acesso em: 24 de abr. de 2017. 


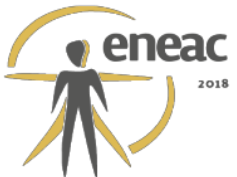

AZEVEDO, Giselle Arteiro N. Arquitetura escolar e educação: um modelo conceitual de abordagem interacionista. 2002. 236 f. Tese (Doutorado) - Curso de Engenharia de Produção, Ufrj, Rio de Janeiro, 2002. Disponível em: <http://www.fau.ufrj.br/prolugar/assets/g_arteiro.pdf>. Acesso em: 19 mai. 2017.

BIGUAÇU. Câmara Municipal. Lei Complementar ํㅜ 356/83, de 09 de março de 2009. Institui o Código de Obras e edificações para o município de Biguaçu. Biguaçu, SC, 09 mar. 2009. Disponível em: <https://leismunicipais.com.br/codigo-de-obras-biguacu-sc>. Acesso em: 28 abr. 2017.

Câmara Municipal. Lei Complementar no 12/2009 de 12 de fevereiro de 2009. Institui o Plano Diretor de desenvolvimento municipal, dispõe sobre as normas, fixa objetivos e diretrizes urbanísticas do município de Biguaçu e dá outras providências. Biguaçu, SC, 12 de fevereiro de 2009. Disponível em: < https://leismunicipais.com.br/plano-diretor-biguacu-sc>. Acesso em: 28 de abr. de 2017.

BRASIL. Constituição Federal de 1988. Promulgada em 5 de outubro de 1988. Disponível em <http://www.planalto.gov.br/ccivil_03/constituicao/constituição.htm>. Acesso em 10 de mai. de 2017.

Ministério da Educação. Secretaria de Educação Fundamental. Lei de Diretrizes e Bases da Educação Nacional. (Lei n. 9394/96). Brasília: MEC, 1996.

Ministério da Educação. Secretaria de Educação. Parâmetros Básicos de Infraestrutura para Instituições de Educação Infantil. Brasília: MEC, SEB, 2006.

Instituto Brasileiro de Geografia e Estatística (IBGE). Censo Escolar de Biguaçu, 2015. Disponível em <http://cidades.ibge.gov.br/xtras/perfil.php?codmun=420230>. Acesso em 23 de abr. de 2017.

CARVALHO, Telma Cristina Pichioli de. Arquitetura escolar exclusiva: construindo espaços para educação infantil. 2008. 342 f. Tese (Doutorado) - Curso de Arquitetura e Urbanismo, Universidade de São Paulo, São $\quad$ Carlos, 2008.2 Disponível <http://www.teses.usp.br/teses/disponiveis/18/18141/tde-06022009-150902/pt-br.php>. Acesso em: 10 mai. 2017.

CAVALIERE, Ana Maria Villela. Educação integral. Educação Social, São Paulo, v. 23, n. 81, p.247270, 2002. Editora: CEDES. Disponível em: <http://www.scielo.br/pdf/es/v23n81/13940.pdf>. Acesso em: 24 abr. 2017.

CORPO DE BOMBEIROS DE SANTA CATARINA. NORMA DE SEGURANÇA CONTRA INCÊNDIOS - INSTRUÇÕES NORMATIVAS (IN) 9: Sistemas de Saída de Emergência. 2014. 46 p. Disponível em: <http://www.cbm.sc.gov.br/dat/images/arquivo_pdf/IN/IN_29_06_2014/IN_09.pdf>. Acesso em: 29 abr. 2017.

EBOLI, Terezinha. Uma Experiência de Educação Integral. São Paulo: Inep, 1969. 84 p. Disponível em: <http://www.dominiopublico.gov.br/download/texto/me001840.pdf>. Acesso em: 03 abr. 2017.

GAETE, Constanza M. JolasPlaza: a brincadeira como ferramenta de desenho urbano. ArchDaily Global (online), 2015. Traduzido por Romullo Baratto. Disponível em: $<$ https://www.archdaily.com.br/br/768697/jolasplaza-a-brincadeira-como-ferramenta-de-desenhourbano>. Acesso em: 23 de abr. de 2017.

GONÇALVES, Antônio Sérgio. Reflexões sobre educação integral e escola de tempo integral. Cadernos Cenpec, Pará, v. 1, n. 2, p.129-135, 2006. Universidade Federal do Pará. Disponível em: $<$ http://cadernos.cenpec.org.br/cadernos/index.php/cadernos/article/view/136/168>. Acesso em: 24 abr. 2017.

GUEDES, Elton. Estudo de caso em projeto arquitetônico. 2015. Disponível em: <https://www.tonsdaarquitetura.com.br/single-post/2015/08/04/Estudo-de-Caso-em-Projeto-

Arquitetônico>. Acesso em: 18 mai. 2017. 


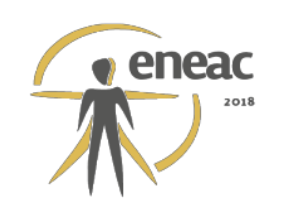

IBAM - INSTITUTO BRASILEIRO DE ADMINISTRAÇÃO MUNICIPAL. Manual para Elaboração de Projetos de Edifícios Escolares na Cidade do Rio de Janeiro. Rio de Janeiro: IBAM/CPU, PCRJ/SMU, 1996.

KOWALTOWSKI, Doris C. C. K.. Arquitetura escolar: o projeto do ambiente de ensino. São Paulo: Oficina de Textos, 2011. 272 p.

KWOK, Natasha. Hibinosekkei + Youji no Shiro Top OB Kindergarten with Rooftop Playground. DesignBoom, 2015. Disponível em: <https://www.designboom.com/architecture/hibinosekkei-youji-noshiro-ob-kindergarten-nagasaki-05-25-2015/>. Acesso em: 28 de jan. de 2018.

MELO, Rosane Gabriele C. de. Psicologia ambiental: uma nova abordagem da psicologia. Psicologia-usp, São Paulo, v. 1, n. 1-2, p.85-113, 1991. Disponível em: <http://pepsic.bvsalud.org/pdf/psicousp/v2n12/a08v2n12.pdfhttp://pepsic.bvsalud.org/pdf/psicousp/v2n 1-2/a08v2n12.pdf>. Acesso em: 10 abr. 2017.

MELO, Larissa Gomes. Arquitetura escolar e suas relações com a aprendizagem. 2012. 34 f. TCC (Graduação) - Curso de Pedagogia, Departamento de Educação, Universidade do Estado do Rio de Janeiro, São Gonçalo, 2012. Disponível em: <http://www.ffp.uerj.br/arquivos/dedu/monografias/lgm.pdf>. Acesso em: 23 abr. 2017.

NOGUEIRA, Michelle. Conhecendo a origem da escola. 2017. Disponível em: <https://www.estudokids.com.br/conhecendo-a-origem-da-escola/>. Acesso em: 10 mar. 2017.

OLIVEIRA, Gabriela Bastos de. Diretrizes arquitetônicas para ambientes de socialização da população infantojuventil em situação de vulnerabilidade social: um estudo de caso no Centro de Educação complementar (CEC) em Florianópolis/SC. 2013. 208 f. Dissertação (Mestrado) - Curso de Arquitetura e Urbanismo, Centro Tecnológico, UFSC, Florianópolis, 2013. Disponível em: $<$ https://repositorio.ufsc.br/bitstream/handle/123456789/107259/320029.pdf?sequence=1\&isAllowed=y >. Acesso em: 29 mar. 2017.

SAVI, Aline Eyng. Condições espaciais e a socialização de crianças e adolescentes em situação de risco: estudo de Caso num Abrigo Institucional. 2002. Disponível em: <https://www.usp.br/nutau/CD/60.pdf>. Acesso em: 19 abr. 2017. 